\title{
RE-DISCOVERY PROCEDURES AND THE LEXICON *
}

\author{
Leonhard LIPKA \\ Dept. of English, University of Frankfurt am Main, West Germany
}

Received Jur:e 1974

1.

1.1 .

In his discussion of the goals of linguistic theory in Syntactic Structures, Chomsky (1957: 50) makes the following remark about the development of linguistics:

\footnotetext{
"Progress and revision may come from the discovery of ncw facts about pa:ticular languuges, or from purely theoretical insights about crganization of linguistic data - that is, new models for linguistir structure".
}

This observation leaves two further possibilities for progress out of consideration: the rediscovery of old 'facts' and the rediscovery of old models In the following, i shall not argue that retrospectic $n$ is the major source of recent developments in the various strains of generative grammar. However, I shall try to show that the rediscovery of certain linguistic phenomena and of certain theoretical approaches toward describing and explaning them has not been without influence on modern inguist. ics. Whether this is to be regarded as vice or virtue depends on eacin inaividual case. As long as it does not mean falling back into is pre-theoretical stage, learning from the endeavours of earlier scholars is clearl! not bli.meworthy.

\footnotetext{
* I am indebted to Dieter Kastovsky, Robert T. King, and James Monaghan for very useful comments on an earlier versio:n of this paper.
} 


\section{2.}

if one has once noticed that old 'facts' and old theoretical constructs reappear more or less well-adapted in modern theories, it is tempting to see rediscovery everywhere. Nevertheless, the evidence for rediscovery is at times overwhelming. It is by now a commonplace observation that se:nantics was first excluied in transformational grammar - as a natural consequence of the structuralist taboo which was carried to extremes in Harris and taken over by his disciple Chomsky - but has since become the central component of the theory of Generative Semantics. The important discovery of deep structure drew attention away from various obvious aspects of surface structure which consequently had to be rediscovered later. The neglect of the morphological component has been noted repeatedly (cf. Dik 1967: 535; Kastorsky 1971: 3; Lyons 1970: 96; Green 1973: 209 fn., $236 \mathrm{fn}$.). Word-formation - which some regard as a sub-level of morphology -. has recently been rediscovered by Halle (cf. Pennanen 1972: esp. 293f). As his article seems to be symptomatic in several ways, I shall discuss it in greater detail in $2.1-2.3$. Surface structure itself, alung wit the theoretical notion of focus, was rediscovered ir Chomsky 197i. As in this article, the influence of intonation is also acknoviledged in Green (1973: esp. 199, 212, 224, 226, 233). Context (including sociai context) - one of the most central notions of Firthian and $\mathrm{N}_{\mathrm{e}}$-Firthian linguistics ${ }^{1}$ - makes its reappearance in Lakoff 1972 as a factor which determines linguistic competence (cf. also Binnick 19?0). The notion of presupposition, finally, goes back to an article by Frege called: "Über Sinn und Bedeutung", which was published as far back as 1892 .

\section{3}

\subsection{1.}

Old theoretical insights have also been taken up anew in recent research Perhaps the most influential concept is that of the 'feature', which first reappeared in 1963 in the guise of the 'marker/distinguisher' dichotomy in Katz and Fodor's Structure of a Semantic Theory, and later revolutionalized transformational grammar in Aspects in the form of contex-

${ }^{1}$ For a re-evaluation of Neo-Firthian linguistics cf. Monaghan, forthecming. For 'context of situation' cf. Lyons 1966. 
tual, phonological, selectional, semantic, and especially syntactic features. As is well known, the concept of feature as a distinctive non-segmental element was first developed in the phonological theory of the linguistic school of Prague. The view of the phoneme as a bundle of simulianeous distinctive features can be traced back to a definition given by Jakobson in 1932 (Vachek 1966: 46). It was the parallelism between the problem of cross-classification in syntax and in phonology which led Clunsky (1965: 79-83) to adopt the concept of distinctive feature and use it also in sy'ntax. Ir: Chomsky 1965 the semantic feature was only negatively defined. ${ }^{2}$ Wenreich (1966), in his attempt to constrict a semantic theory which was meant to be compatible with $A s_{i}$ ects, consistently applied the concept to semantics, distinguishing two types of sets of semantic features ('clusters' and 'configurations') and int roducing 'transfer features'.

\subsection{2.}

Arother case in point, where the insights of the 1930's have become fruitful thirty years later, is the theory of 'markedness' developed iit The Sound Pattern of English. The authors openly acknowledge (Chomsky/Halle, 1968: 402) their debt to the phonologists of the Prague Circle with regard to the notion of marked and unmarked values of features. The concepts of markedness and neutralization are also taken up in Cairns 1969 and put to use for an explanation of a number of uriversals.

\subsection{3.}

\subsubsection{1.}

Perhaps one of the most recent rediscoveries, and most wide-spread current vogue words, is presupposition. As already mentioned, the term goes back to 1892, as used by the philosopher Frege. I have traced the application of the concept in linguistics to Fillmore 1966, where 'supposition rules' are postulated. In Fillmore's example When did you come to the shop? the 'supposition' inherent in come concerns the speaker of the sentence, not its surface subject. Under the influence of Fillmore (as is openly acknowledged) McCawley (1968b: 267) then proposes to replace the theoretical construct 'selection restrictions' of 'lexical items'

${ }^{2}$ For a discussion of the theoretical status of semantic features cf. Lipka 1972: 33-37, 42-55, and King 1974: 3.1.. 
by "presuppositions about the intended referent". Bachelor is said to have the meaning 'unmarried' and the presuppositions 'human, male, adult'. In Fillmore 1969/71 presuppositions or 'happiness conditions' are regarded as properties cf lexical items, viz. as "the conditions which must be satisfied in order for tile item to be used 'aptly' "'(370), but also as properties of sentences, viz. "those conditions which must be satisfied before the sentence can be used in any of the functions [i.e. as a question, command, ascertion, or expressing feelings, LL] just mentioned" (380). Negation is used as the test for discovering presuppositions (380), and the procedure is illustrated with the sentence Please open the door and the lexical item bachelor.

\subsubsection{The ambiguity, or rather polysemy, of presupposition is not} surprising if we consider it as a deverbal derivative from the two-place verb presuppose. Although, diacironically, presupposition is a loanword, it is synchronically analysab'e as a suffixal derivative in -ition, parallel to apposition, supposition, uefinition, addition, apparition, rendition. The productivity of this type is quite restricted. Presupposition is thus basically relational: either lexical items or entire sentences may presuppose something, and what is presupposed are certain conditions for the use of these items or sentences. The most general use of 'presupposition', which is at the same time the original philosophical one and which is implied by more specific conditions, is that the thing talked about, i.e. the 'intended referent', really EXISTS. Other, more specific, presuppositions are the belieis which a speaker of a sentence has who utters particular lexical items or sentences. This specific reaciing, too, is predictable, if we derive the complex item presupposition from an underlying sentence 'Sorneone presupposes something' (cf. 2.2.1, 4.1.2). Thus, there are at least two different lexicalizations of p.esupposition, one referring to the existence of the intended referent, the other to the specific conditions for the correct (happy, apt) use of particular lexical items or sentences. The confusion over the term 'presupposition' has been deplored repeatedly (Fillmore/Langendoen 1971: vi; Garner 1971: 23, 42). It is probably an effect of the processes of 'hypostatization' (cf. 4.1.2) and of 'lexicalization' (cf. 2.2.1). This has prevented many people from realizing that 'presupposition' is not a substance or property existing independent of previous assumptions, but rather a theoretical construct.

\subsubsection{The rediscovery of Frege's presupposition was relatively consci-}


ous, and is rather restricted to the term, i.e. the 'signifiant' of this metalinguistic lexical item. The same concept, denoted hy the term Gebrauchsbeding,ungen, could have been rediscovered in a more recent publication, viz. Leisi's (1971) Der Wortinhalt. Seine Struktur im Deutschen und Englischen (4th ed.; 1st ed. 1952!). According to Leisi, language as a whole, as well as the individual word, is a 'Brauch', i.e. a custom, parallel to other ci toms of a particular society. The use of a specific word is determined by 'Bedingungen', i.e. certain conditions, which may be linguistic but also extralinguistic. The 'speech act' (not identical with the current use or this term!) ("Der Sprechakt als Ganzes") is a sequence of customs: "Sprechakte unterscheiden sich also durch ihre Natur als Brauchsfolge von den anderen Briuchen, die meistens einzeln erscheinen" (19). Leisi claims: "Jeder Sprechakt ist normalerweise doppelt bedingt, durch die aussursprachliche $B \in$ dingung und durch die innersprachliche (=begleitende Sprechakte)" (19, the emphasis in both quotations is Leisi's). A great many English and German words are discussed contrastively in the book, and their 'Gebrauchsbedingungen' are investigated in detzil and with greai ingenuity. The book remains an invaluable source for theoretical and practical conclusions about English and German.

1.3.3.4. A final remark about presupposition will not seem out of place. Considering recent developments in linguistics, it seems to me that the introduction of this term and concept is an expression of the current trend against formalization. Students as well as scholars are bored with bearning new notations every day, only to find out that by the time they have acquired the technical skill to apply them, the theories behind the notations are no longer valid. The technical problems of some elaborate systems also make access to the underlying theories very difficult. With some tineoreticians one cannot help wondering whether this effect was not intended all along, to impress the reader and to fight off uncomfortable qucstions.

2.

2.1.

2.1.1.

A striking example of rediscovery as well as an illustration of certain procedures unfortunately rather wide-spread in current linguistics is 
Halle's article Prolegomena to a Theory of Word Formation (1973). He believes that this field "has been studied only to a very limited extent" and hopes "to attract others into research on this topic" (3). One wonders if this invitation is addressed to certain researchers who have already accomplished a considerable amount of basic work in the field. Amongst those names which immediately spring to mind in this context one might mention several, beginning with Botha, Brekle, Coseriu, including Dokulil, Erben, Fleischer, Gauger, Gruber, Hansen, Hatcher, Henzen, Kastovsky, Koziol, Lees, Ljung, Malkiel, Marchand, Morciniec, Motsch, Neuhaus, Rohrer, Stein, and finishing with Weinreich and Zimmer. This research has been openly published in book-form or journals and is not confined to mimeograr: hed papers which are only available within a closed circle. The above list can easily be augmented from the extensive bibliography in Marchand 1969 and from Stein 1973. Halle only mentions Chapin, Jespersen, and an unpublished paper by Siegel. Apparently, he compietely ignores the fact that Marchand (amongst others) has developed a comprehensive theory of word-formaticn, and has applied this theory tc a full-scale asscription of English word-formation. ${ }^{3}$

\subsection{2.}

Halle starts off with the claim that speakers of English know that adjectives such as iransformational are "composed of the morphemes" trans-form-at-ion-al and that "facts like those" have to be formally represented in a theory of word-formation. The proposed segmentation is by no means a 'fact' but must be based - either implicitly or explicitly - on a theory, as is the case with any analy tical procedure in linguistics, of which segmentation of utterances or words into morphemes (morphs) is one of the most important instances characterizing a whole era of linguistics, viz. structuralism. For example, anyone only slightly familiar with the methods of structural descriptive linguistics would probably question treating - at - in transformational (or - $i$ - in serendipity which Halle discusses later) as a morpheme or an allomorph ${ }^{4}$ but would prefer a segment -ation as a linguistic sign. It is true, though, that "struc-

${ }^{3}$ The first edition of this standard work appeared in 1960 and was reviewed in a number of journals. Cf. Brekle-Lipka 1968, Marchand 1969, Lipka 1971a, Penranen 1972, Kastovsky $1974 b$.

${ }^{4}$ Of course this is not to be confused with -ate as in consulate, passionate, acetate, hyphenate; cf. Marchand 1969: 254-250. For -ation sce Marchand 1969: 259-261. 
turalism' was not a monolithic block, and that various 'structuralists' held different views at different times. Any improvement on standard work and the great mass of informed opinion is certainly to be welcomed. However, one might expect such developments to be justified against other work in the field. ${ }^{5}$ Halle further suggests that e.g. the entry for write must contain the information that it belongs to the 'non-Latinate' part of "?:e vocabulary. This observation is handled on a higher level of generaization by Marchand's distinction between word-formation on a native and on a foreign basis.

\subsection{3.}

The "idiosyncratic characteristics of individual words" are discussed at length bv Halle. This topic is the subject of a whole book (Botha 1968) on thie function of the lexicon in a transformational-generative grammar. Starting from Chomsky's hypothesis about the lexicon as "the full set of irregularities of the language" Botha treats nominal compounds in Afrikaans in grea $i$ detail and postulates a phonological dictionary and a phonological matching rule. The theoretical model proposed by Botha is strongly influenced by Weinreich's thoughts (cf. Botha 1968: 245; Weinreich 1966: 445, 1969: 59, 74). Halle (4f) distinguishes three types of idiosyncrasy in word-formation: (a) semantic, (b) phonological, and (c) restrictions of productivity, and suggests accounting for them with "a special filter" through which words have to pass after being generated by word-formation rules. This solution exactly corresponds ${ }^{6}$ to the post-

5 Thai segmentation in morphology is a highly sophisticated matter will become obvious to any reader of Matthews 1972. Based on examples from Latin verb conjugation, Matthews discusses various models of inflectional morphology in relationship with the problem of evaluation procedures. Difficulties which arise for an Item and Arrangement $n_{1}$ odel - in particular when dealing with intlecting languages - lead him to consider the status of the word as a morphological unit (cf. esp. 96-103). Matthews arrives at the conclusion "that for Latin and other infecting languages, some form of the Word and Paradigm approach should be preferred" (47). Matthews' comprehensive investigation proves the point made in Dik 1967 that - with regard to inflection - the emphasis of transformational descriptions on Modern English "has not confronted the theory with all the intricacies that may be met in this field" (357). For a sketch of my own views on the 'morpheme' cf. 2.2.3.

${ }^{6} \mathrm{Cf}$. Weinreich 1969: 74: "The role of the filtering device is to differentiate, among possibie words, those that are established from those that are not" [my emphasis, LL]. Cf. the notions 'possible lexical items' and 'gap in the lexicon', both used currently in Generative Serantics. Cf. e.8. McCawley 1968a: 74; 1971: 19, 21f; Green 1973: 210, but alsu Lipka 1968. Cf. the distinction between 'accidental' and 'systematic gap' in phonology and the 'accidental semantic gap' in Chomsky 1965: 169f. 
'Wition of an 'idom comparison rule' (later'matching rule') for (a) in Weinreich's 1969 model, and the "phonological matching rule" for (b) in Botha 1968. The restrictions under (c) - or more precisely all three types of restrictions on rulcs. semantic, phonological, productivity - can be accounted for in another theoretical framework by Coseriu's concept of 'norm' (cf. Marchand 1969: 17, 57; Stein 1971; Neuhaus 1971). Although Weinreich does not claim that his theory, published in 1969 but developed and proposed earlier (lectures celivered during the 1966 Lirguistic Institute at UCLA), solves all the problems of word derivation; his concepts of a 'simplex dictionary', a 'complex dictionary', an 'idiom list', 'familiarity ratings', and a 'matching rule' seem to be extremely useful and important. They are consistently applied in Lipka (1972; cf. esp. $84 \mathrm{ff}, 128 \mathrm{ff}$ ).

\subsection{4.}

Discussing the distinction botween 'derivational morphology' and 'inflectional morphology' Hal'e (6) states: "I know of no reasons why the list of morphemes should not include also the inflectional affixes". At least two reasons might have been found in Motsch 1962: the place of inflectional morphemes in the constituent structure of complex lexical items, and the different degrees of combination potential of lexical and grammaticai morphemes. Inflectional morphemes in English and German are usually placed at the end of words, after all derivative morphemes have been added. Combination with the former is much less restricted than with derivational suffixes. Motsch (1962: 39) also sets up rules exactly like the "word formation rules' suggested in Halle (10). The relationship between inflexion and word-formation is treated in great detail within the framework of Chomsky/Halle's Sound Pattern of English in Wurzel (1970: 15-104). The investigation of inflectional morphology by Matthews (1972) seems to indicate that, at least in Latin, it will probably be advisable to separate word-formation strictly from inflection. Halle mentions that word-formation rules will have to include information on selection restrictions. He seems hardly aware of the difficulties of establishing the correct selection restrictions even for very simple everyday words, ' or of the problem whether 'selection restriction' as such is a justifiable concept in linguistics.

${ }^{7} \mathrm{Cf}$. the review of various linguistic judgments on the selection restrictions of sa: in Lipka 1972 (48-51) and King 1974 (3.2). The possibility of treating such restrictions with the notion of presupposition is not mentioned by Halle. 


\section{2 .}

\subsection{1.}

A theory of word-formation must include an explanation of the fact that complex lexical items differ semantically from the sum of their components. This could be done with the concept of 'lexicalization' which entail: ${ }^{+}$: addition of semantic features. Such an approach is sketched in Lirka (197 ia). The term is not used here in the way it is used now within the framework of Generative Semantics, i.e. for the insertion of lexical items, or the surface realization of a configuration of atomic predicates. It is rather meant to indicate ${ }^{8}$ that complex lexical items, once they are created from smaller ulements and used repeatedly, can become lexemes in their own right, with a loss of motivation (and perhaps also anclysability), and acquire certain specific semantic features. Lexicalization is tied up very closely with 'hypostatization' (cf. 4.1.2), but the latter process also affects simple lexical items. The lexical item lexicalization itself may serve as an example. As I use it here, I follow the tradition established in Marchand's Categories in 1960. Both this meaning of lexicalization and the one found in Generative Semantics can be said to go back to an underlying sentence 'Something becomes (a) lexical (item)' or probably better from its causative derivative 9 'Someone causes sumething to become (a) lexical (item)'. However, in Generative Semantics, the underlying pro-form something refers to prelexical elements, or atomic predicates, while in Marchand's and my own use it refers to the morphemes as elements of surface structure which make up a new lexical item that becomes a semantic unit. 'Surface structure' is not used here in the specific technical sense as defined in some transformational-generative model, but referring to anything directly observable as opposed to a more abstract 'underlying structure'.

\subsection{2.}

It is no secret that the process of lexical insertion is a mystery far from being solved in the framework of Interpretative or Generative Semantics

${ }^{8}$ Cf. Lipka 1972 s.v. index. The noun is of course a nominalization of the verb lexicalize which only (?) occurs in the passive, as the agent is never expressed. This is a pnint worthy of attention.

9 The second underlying structure would account for this usage, and implies an obligatory eiement CAUSE. Cf. Kastovsky 1973. 
(cf. Green 1973: 206-208, 210). Since McCawley's article Lexical Insertion in a Transformational Grammar without Deep Structure (1968) which despite its title does not clarify but only raises the issue - relatively little progress has been made. I suggest that the concept of lexical insertion should be supplemented or replaced by the notion of morphemic insertion. For various reasons it is impossible for me to describe here my views on this problem, or to develop an alternative theory of word-formation. A few hints have been given above. As a sketch, I can add that I largely agree with the conclusions drawn in Kastovsky 1973, and therefore - as in Lipka 1972 - er. brace many of the assumptions of Generative S mantics. If, however, as Kastovsky and I believe, prelexical semantic elements such as CAUSE DO BECOME NEG MILITARY are converted into complex lexical items such as demilitarize, and the prelexical element (or atomic predicate) "MILITARY is replaced by the adjective military, the features BECOME NEG by the prefix de-, which is attached to military, and the features CAUSE DO by the suffix -ize" (Kastovsky 1973: 270), then it must be morphemes that are inserted, not lexical items. ${ }^{10}$ This, o." course, means a return to surface structure, although, not at the expense of neglecting underlying structure (c1. Kastovsky 1971: 8f). As opposed to Chomsky and Halle, one need not rediscover surface structure if one has never given it up.

\subsection{3.}

At this point I should like to sketch briefly my views on the 'morpheme'. I believe that morphemes are the smallest linguistic signs, i.e. meaningful observable segments in : which elements of content (e.g. semantic features) are related in an arbilirary way to elements of expression. As opposed to some varieties of structuralism I do tiot require allomorphs, i.e. phonologically or morphologically conditioned variants of a morpheme, to have identical or even sin ilar phonic shape. Thus, /iz, z, s, a n/, and $\phi$ are all considered allomorphs of the same plural morpheme in English (cf. Lipka 1969). In my viev 'morphemes' are therefore essentially semantic units. This also becomes evident from my adoption of the concept of 'zero' in linguistics, since 'zero-allomorphs' and 'zero-morphemes' have no phonic expression at all (cf. Kastovsky 1968: esp. 31-53). Fol-

\footnotetext{
10 Kastovsky's particular analysis in which de - replaces BECOME NEG may be questioned if one believes that in the inchoatives black/en, redd/en, warm/ $/$ (which are homonymous with the corresponding causatives) the suffix -en and the zero-morpheme represent BECOME.
} 
lowing Weinreich (1966: 432f), I believe it is useful and descriptively adequate tc distinguish between 'major' and 'minor classes of morphemes', which roughly corresponds to the more traditional distinction between "lexical' and 'grammatical' morphemes. I disagree with Weinreich on the nature of categorial features such as [+Noun, +Adjective] which he believes to be "semantic in the full sense of the word" (433). Both classes of morphemes then, in my view, can be represented as a triplet of features, ch could be termed 'phonological', 'categorial' (also including syntac ic infes mation), and 'semantic' features. I am fully aware of the fact that this is not sufficient for a complete specification of lexical entries for morphemes in some type of dictionary or lexicon.

\subsection{4.}

An explanation of the phenomena mentioned in 2.2 .1 and 2.2 .2 is never seriously attempted in Halle's article. The ambiguity of lexicalization, or rather, the derivation of the two different, but closely related, lexical items by the same very general derivative process could never be explained by anything resulting from Halle's Prolegomena. Certain extremely productive word-formation processes are not even touched upon in his paper, such as compounding, prefixation, and zero-derivation (cf. Marchand 1969: 11-127, 129-208, 359-389; Kastovsky 1968).

\section{3.}

Two questions must be raised with regard to Halle's article. Firstly, did he tar e into consideration the large amount of basic research which had previously been done on the subject of word-formation? Secondly, has Halle brought up any problems which have not already been treated, or proposed any : slution for such 1roblems which have not been offered elsewhere? It seems that the answer to both these questions is no, and for this reason Halle's remarks can not be regarded as "Prolegomena to a Theory of Word Formation".

3.

3.1.

The distinction between the transformationalist and the lexicalist hypothesis (leave alone Chomsky's conversion from the former to the 
latter position) is not mentioned once in Halle's article. This is all the more surprising, since the reasons why Chomsky adopted the lexicalist position for 'derived nominals' in $1968^{11}$ are exactly the same as those which led Halle to put forward his Prolegomena: semantic and syntactic idiosyncrasy and restrictions on productivity. While stating that wordformation processes "are typically sporadic and only quasi-productive" (Chomsky 1965: 184f), Chomsky in Aspects still derives refusal, destruction from the respective verbs by a nominalization transformation, because the process is said to be productive. This is a solution which is irlily within the generative-transformational spirit, as it accounts both for creativity in language and irregularity of the superficial surface structure. It shows the greatest possible generalization, and, at the same time, assigns secondary importance to surface phenomena. This is in keeping with the generally recognized observation that even highly productive morphological processes, such as the formation of plurals or past tense forms. have exceptions - such as irregular nouns or verbs (cf. Lipka 1968 esp. $128 ; 1969)$. But even for 'quasi-productive processes' such as the formation of horrify, terrify telegram, phonograph Chomsky in Aspects arrives at the conclusion: "it is clear that from the point of view of both the semantic and the phorological interpretation it is important to have internal structure [my ernphasis, LL] represented in these words" (186). In Remarks on Nominalization, however, Chomsky abandons his earlier approach to 'derived nominals'. Newmeyer (1971) has tried to show that the arguments for doing this "give at least as much support to a transformational analysis" and concluded that "insufficient evidence is presented in Chomsky 1970 that derived nominals should not be derived via a transformational rule" $(786,796)$. One of the reasons for abandoning the earlier transformational hypothesis, was so as not to have to abandon another highly questionable hypothesis, viz. that transformations do not change meaning. ${ }^{12}$ This is difficult to understand, since the concept of 'transformation' like that of 'deep structure' has undergone so many fun-

1 Chomsky never explicitly defines 'derived nominals'. The article, fir.t appuaring in print as Chomsky 1970, had circulated in mimeographed form as Chomsky 1968 and is labelled Chomsky 1972 in Halle's article, thus inducing the naive reader to believe this io be a recent paper. This is a case of rediscovery of a whole article.

12

Chomsky (1970: 189): "I The appeal to this ... device] reduces the hypothesis that transformations do not have semantic content to near vacuity". Cf. Hall Partec 1971. As a semantic change does not occur with 'gerundive nominals', Chomsky in this case retains the transformational hypothesis. Cf. Chomsky 1970: 215. 
dan ental changes since 1957, when it was postulated to relate surface structares such as active and passive sentences.

\section{2.}

\subsection{1.}

The irregularities of the lexicon and inore specifically the "thoroughly bas a dizec, irregular, and unsystematic derivational morphology" (79) of Lnglish 1: also one of the starting-points of a short article in which Green (1969) tries to establish the notion 'related lexical entry'. Overstrcssing - ir my opinion - the idiosyncrasy of the lexicon at the expense of regu'arity and generalization (as is currently dorie in many articles, in ludin' unfortunate conclusion: "that I view all relations between meanings (related or not) and forms as entirely arbitrary" (79, Gieen's emphasis). As it stands, this seems to be a complete denial of the possibility of ever developing a theory of word-formation, and it also seems to contradict Green's later statement: "I am incapable of providing a clearly defined theory of relatedness among lexical entries. My main purpose here, howcver is to make it clear that it is not merely desirable, but necessary, that we have one". ${ }^{13}$ She claims that the protlem she raises "deserves at 'east ten dissertations of study", but apparently has not read a single orte of the many books written on the subject (cf. the bibliography in Marchand 1969 and also Stcin 1973).

\subsection{2.}

There is no contradiction, however, in the two remarks quoted above, if the first one is interpreted as another case of rediscovery. If it is taken as expressing nothing more than Saussure's fundamental axiom of the 'arbitraire du signe linguistique', then no conflict arises. Such an assumption would be supported by other observations. Green sets up a distinction between 'lexical entries' (which are trees, i.e. configurations of semantic material) and 'lexical items' (which are phonological forme with indications of morphologic 5 roperties, or "morphemes without meaning") (79). These have a striking resemblance to Sa!ıssure's 'signifié' and

${ }^{13}$ Green 1969: 83. Cf. also Green 1973 (236 fn.): "I confess total ignorasce and failure of intuition regarding the proper iole in generative grammar for derivational as well as inflectional morphology". 
'signifiant'. Of course, for anyone who adopts Saussure's concept of the linguistic sign, the same 'signifian'́ can have different 'signifiés', and such distinct signs are traditionally called 'homonyms' of 'homophones'. Green alleges that for Katz and Fodor and for Fillmore one phonological form necessarily constitutes one lexical entry, and sees her concept of the lexicon, in which phonological sameness does not imply sameness of lexical entry, as radically opposed to this. She has thus rediscovered "homonymy' and 'polysemy'.

\subsection{3.}

Green discusses the question whether intransitive (inchoative) break, which is said to represent an underlying structure such as:

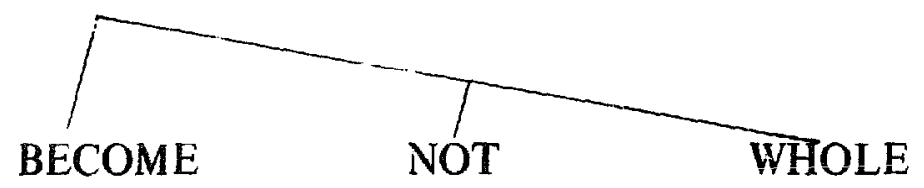

and transitive (causative) break, which can be regarded as a surface realization of:

(2)

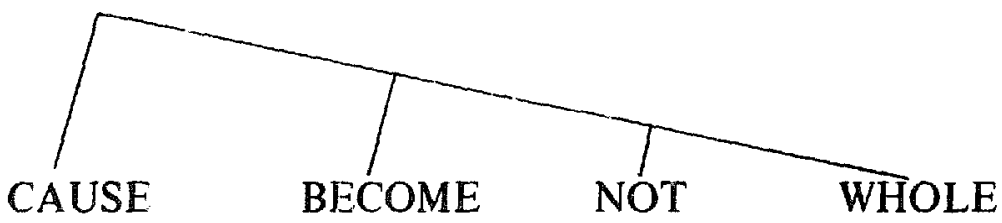

should be considered the same 'lexical entry' ( $=$ 'signifié'). If one believes as Green obviously does - that the phonological form/breik/represents both structures on the surface level, then the question she raises would seem to be pointless. If, however, 'lexical item' is taken to be synonymous with 'lexeme' or 'lexical morpheme' (i.e. as a full linguistic sign), then it is meaningful to ask whether /breik/ is one item, contextually determined as a predicate by its arguments - as in a case grammar approach, where the presence of Agent amounts to the addition of CAUSE - or whether it represents two items closely and derivationally related. The latter solution has to be adopted by anyone who subscribes to the concept of 'zero-derivation'. ${ }^{14}$ It is supported by proportional equations such as legal: legal/ize $::$ clean: clean/ $\emptyset$ and atom: atom/ize $:$.

14 For this concept cf. Marchand 1969, Kastovsky 1968, and Lipka 1972 s.v. index. For causative zero-derived verbs cf. Kastovsky 1973. 
cash: $\operatorname{cash} / \emptyset$. With such an approach the transitive break/ $\emptyset$ is a zero-derivative from the intransitive break which is the surface representation of an underlying structure like (1). Similarly, the verb punt/ $\phi$ 'use a punt' is a zero-derivative from the noun punt. This derivative pattern is highly productive; however, as is the case with even the most regular grammatical processes, it is not without restrictions. 15

\subsection{4.}

The stiond observation, besides lexical idiosyncrasy, on which Green bases her conciusion that all relations between meanings and forms whether related or not - are arbitrary, is the belief that "differences among languages are primarily lexical" (79). Although it is only natural that different linguistic systems should use different linguistic signs, this again overstates irregularity at the expense of possible generalization. Many articles by Marchand, which reflect work on languages such as English, French, German, and Turkish, reveal striking correspondences in the derivational processes of these languages, although, not unexpectedly, there are differences. Recently, Rose has shown extraordinary parallels in the derivational constraints of such unrelated languages as English and Indonesian (Rose 1973: cf. esp. 509f).

\subsection{5.}

Green demonstrates (80) that inchoative break and causative break/ $\phi$ are not "tokens of the same lexical entry" by using "behaviour as anaphora" as a test. A second "test for same lexical entry" is conjunction reduction (cf. Weydt 1973: 576f). I believe that this procedure, which obviously is a semantic test, is only a variant of Weinreich's and-test, which was used to show that there are two different items practice in practice medicine and practice piano since they cannot be conjoined. ${ }^{16}$ The use of objectively verifiable tests, not as a procedure to discover something naturally pre-existent, but as a motivation and justification for theoretical assumptions, seems to be rediscovered more and more often in recent literature. It maly be interpreted as a growing distrust in

${ }^{15} \mathrm{Cf}$. Green 1969: 85f; the verbs in fn. 3 (except go, come, die, believe and their causative equivalents) are all zero-derivatives. The verbs in Green's table I and II belorig to Jespersen's 'Move and Change-Class'; cf. Lipka 1972: 63, fn. 72. Cf. the distinction in traditional German grammar between 'Zustandsverben' and 'Vorgangsverben'. and esp. Leisi 1971: 46-70.

16 Cf. Lipka 1972: 56-61, esp. 60. Weinreich is not mentioned in Green 1969. 
the analyst's intuition, which had come to dominate linguistics at the expense of empirical objectivism with the advent of TG-grammar. We shall deal with this in the following.

\section{4}

\section{1}

4.1.1.

The term discol ry procedure seems to have been coined by Chomsky ${ }^{17}$ ir 1957. Apparently, like the lexical item taxonomic, it has since acquired $r c$ ther unfavourable connotations. This is not an unusual fate for complex lexical items, owing to the process of lexicalization. As with potentially all lexemes, even in technical terminology, there is of ten confusion as to its exact denotation (or reference). As a rusuit of ambiguity, or better vagueness (sec below), and negative evaluation, ${ }^{18}$ the term test is tociay preferred for one me aning of discovery procedure.

\subsection{2.}

As pointed out by Leisi as early as 1952 , there is a tendency for all lexical it ms, whether simple or complex, to imply that the entity denoted by a word actually exists as a substance or person - something he calls "Hypostasierung durch das Wort". ${ }^{19}$ We have to be careful to check, whether the thing suggested by the lexemes discovery procedure is actually to be found with a particular structuralist linguist, or whether it is onIy an 'hypostasis', created by illegitimate generalization or the suggestive power of the surface structure elements. The definition of discovery procedures may impose very strong requirements, viz. that such procedures autornatically, mechanically, and practically produce a set of rules, i.e. the rules of a grammar, or quite simply the grammar of a language. ${ }^{20}$

17 Chomsky 1957: 51. Cf. Lyons 1968: 157; Chafe 1970:6,99; Cruse 1973: 15f. It is not used in Nida 1949, Fries 1952, and Gleason 1961. For a survey of 'discovery procedures' in the "American structuraist school" cf. Miller 1973.

${ }^{18}$ For a possible feature 'Negative Evaluation' see Lipka 1972 s.u. NegEv in the index. For the use of test instead of discovery procedure cf. Chafe 1970: 99, Cruse 1973: 15.

${ }^{19}$ Leisi $397: 25$. This is the 4 th edition of the book which relies on research going back as far as 1946 as mentioned in the preface. There is also reference to 'hypostatization' in Firth's wotk.

20 if. Chomsky 1957:50f, 56, 1965: 19; Lyons 1968. 157, and Chate: "some recipe that could be applied to phonetic data ... 10 prodice the grammar of a language" (1970:6). Grammar is here used in the sense introducisd by Chomsky as 'grammatical model'. 
The derived action-noin or result-noun discovery, more precisely the verb discover as the basis of derivation, presupposes (also in the original Fregian sense) that the object (in both senses) is already in existence. Following Marchand's theory that complex lexical items, seen as 'reduced syntagrias', can be derived from sentences - which is in perfect, agreement with Weinreich's view ${ }^{21}$ that lexemes have the underlying structure of sentences (which is also one of the axioms of Generative Semantics) - disco 2 , can be said to be derived from 'Someone discovers something'. 'he vagueness, but not the ambiguity, of discovery results from the fact that in the reduced syntagma the object 'something' is not expressed in surface structure, ${ }^{22}$ and the pro-form may refer to a variety of things (rules, a grammar, universals). Following Binnick (1970), I here distinguish 'vagueness', in the sense of referential indeterminacy or unspecifiedness, from 'ambiguity', as a property of linguistic constructions. The result-noun discovery (like e.g. handout) may refer to an infinite varie iy of extralinguistic objects and is therefore 'vague'. The two-way distinction between action-noun and result-noun is one of systematic 'ambiguity', which is explained in Marchand's theory with the help of different 'types of reference'. In this model, the action-noun discovery is a 'Predication type', while the result-noun discovery is an 'Object type'. As I tried to show in the preceding remarks, the technical term 'discovery procedures' is far from being unproblematic. It is definitely referentially vague. Strong requirements may be imposed for its use, such as that the denotatum automatically, mechanically, and practically produce the rules of a particular grammar.

${ }^{21}$ Cf. Weinreich (1966: 446): "every relation that may hold between components of a sentence also occurs among the components of a meaning of a dictionary entry", and his remark that "the same co:figuration" is present in the singie item dentist as in the combination fix+teeth (424). Marchand's ideas were strongly influenced by Bally' $s$ views on 'syntagma' and 'transposition' which were first published in 1932. Cf. Lipka 1971a: 217f, esp. fn. 22. They were first formulated explicitly by Marchand in 1960, certainly not without the influence of transformational grammar, especially Marchand's controversy with Lees. In fact, this part of Marchand's theory is a strong variant of the trantiformational hypothesis, first held by Lees in 1960.

${ }^{22}$ For the coinsequences of deriving complex lexical iterns (=reduced syntagmas) from sentences (=full syntagmas) cf. Lipka 1971a: 219ff, and Marchand 1969: 32ff where 'types of reference' are developed. For an application of this concept to der ived nouns such as blowout, blowup, dropout, handout etc. and their polysemous meanings cf. Lipka 1972: 138-152. If both full and reduced syntagmas are to be derived from the same underlying structure, consisting of configurations of semantic mate ial, the consequences for the theory are considerable. Cf. Kastovsky 1973, and for 'ambiguity' vs. 'vagueness' 1974a: 14-16 and Birnick 1970. In Lakoff 1970 an unformalized 'test' for a similar but not identical distinction is usod. [ \pm Intentional] is said to be matter of 'ambiguity' not of 'vagueness'. 


\subsection{3.}

But discovery procedures may also be defined with lesser requirements, denoting certain analytic techniques (cf. Cruse 1973: 15). If it is stripped of its associations with American taxonomic structuralism - and the resulting connotations - it may be used simply to denote a more or less formalized empirical technique, which serves to establish beyond subjective intuition that certain elements are present, or even that certain theoretical constructs may be postulated. It is true that there is a contradiction in terms if discovery procedures are used for the motivation or justification of theoretical constructs. However, incorrectness of denotation has never hindered the use of 'false' words, as George Orwell's 'newspeak' demonstrated long before $19 \delta 4$ or $1974 .{ }^{23}$ Nevertheless, it is probably better to use the neutial test instead of discovery procedures. Perhaps transformation and deep structure, whose meanings have changed so often and so radically, should also be replaced by less confusing terms.

4.2.

\subsection{1}

Let us now look at a fe - examples of formal procedures which have been used in linguistic research to support theoretical claims, to recognize postulated elements, or to justify an assumption about underlying structure which is not directly observahle. Cibservation and recognition naturally are not completely independent of certain basic assumptions made by the analyst or the model set up by him, be it ever so elementary. A neat division of inductive ard deductive reasoning is neither possible nor desirable.

\subsection{2}

Discontent with informal and incoherent definitions of the parts of speech in traditional grammer induced Fries (1952) to develop procedures "to discover inductively from the recorded materials", on the grounds of distribution ard using the technique of substitution, the parts of speech or 'form-classes' of English (74). He chooses three sentence-

\footnotetext{
32 Cf. Bolinger 1973, and examples quoted there, such as protective reaction, or initial investment (for down payment). In relatively recent $W_{\text {ate }}$ House declarations people misspoke thernseive:, instead of having made incorrect of ialse statements, or simply having lied. Cf. also mothor church (for M.I.T.).
} 
frames that serve as the basis for the substitution tests which permit him, according to the possible positions in the frames, to establish classes of words, without having recourse to meaning. The resulting four 'formclasses', although largely corresponding to the traditional nouns, verbs, aljectives, and adverbs, are not identical with these word classes. ${ }^{24}$ They are not pre-existing natural elements, but theoretical constructs, as is clearly indicated by their labels: class 1 words, class 2 words, etc. In a second sten, this classification is supported by evidence from "formal charact s stics", i.e. the morphological properties of the items. As opposed to this procedure, early transformational-generative grammar had simply tried to subcategorize the intuitively established traditional word classes.

4.2.3.

In a review of Zimmer's book on affixal negation in Language, Marchanu (1966a) first set up a distinction between transpositional and semantic derivation, which was applied to English adjectives in Marchand 1966b. He separates 'transpositional adjectives', such as adjectival, polar, presidential from 'semantic adjectives' such as childish (man) on semantic grounds and by using unformalized transformational relationships. According to Marchand, syntactic position can be used as a test: transpositional adjeciives never occur in predicative position. We may add, that, as a consequence of this, they can also never be graded (* more adjectiv. $a l$, "more polar). The same surface item crn be both a transpositional and a semantic adjective. While a criminal court IS not criminal but 'deals with crime', a criminal lawyer can be either, which accounts for a possible crimir al criminal lawyer. Marchand's 'transposition' corresponds to Chomsky's 'transformational hypothesis', since it is completely regular and does not add semantic features. Marchand's 'semantic derivation' corresponds to the 'lexicalist hypothesis' and can be explained with the help of 'lexicalization'. This concept denotes a basically historical process - although sometimes restricted to a very short time interval. 'Lexicalization' thus shows up one of areas where the Saussurian dichotomy of a synchronic and diachronic approach is not appropriate to linguistic reality (cf. the title of Marchand's book, and Lipka 1966: 41).

${ }^{24}$ For other approaches to the problem of establishing criteria for wore classes, and for the relevance of the concept for word-formation cf. Lipka 1971a. 
4.2.4.

In Jacobs/Rosenbau n 1968 a number of tests are mentioned for determining such constituents of sentences as noun phrases, verb phrases, and auxiliaries. Noun phrases can be recognized by four different tests, which are based on position and transformational potential: 1 . the passive-test (only applicable with objects of transitive verbs); 2 . the interrogative-transformation (for subjects of intransitive verbs); 3 . the reflexivetransformation (for subjects of reflexive verbs); and 4. the cleft sentencetransformation (for embedded sentences functioning as NPs). Only such explicit procedures allow us to generate correctly underlying structures with the appropriate category symbols. It should be noted that word classes and their subclasises (such as derived transpositional or semantic adjectives) are morphological (and at the same time syntactic) categories, while notin phrases are functional (i.e. relational) syntactic categories.

\subsection{5.}

Semantic tests, i.e. pricedures for the discovery of semantic phenomena or the justification of theoretical constructs such as semantic features, have not often been considered as a problem worthy of attention (cf. Lipka 1972: 33-37. 42-61). Weinreich, with the development of the but-test and the and-test (mentioned above) is one of the most prominent exceptions. The but-test, supplemented by the so-iest, has been applied successfully in the semantic analysis of English verb-particle constructions in Lipka (1972: cf. esp. 60f). In Chafe 1970 certain "rough tests" are discussed which arc labelled "rules of thumb" that "are presented only as rough, practical guides, not as 'discovery procedures" ", since "there is not reason to think that a particular semantic fact will be mirrored with 100 percent consistency by some other fact" (99). Thus, according to Chafe, 'non-states' can be distinguished from 'states' by the fact that they answer the question "what happened?", while 'states' cannot occur in the progressive. A number of semantic tests are also discussed in Cruse 1973, and four semantic features for agentivity (volitive, effective, initiative, and agentive) - whose status in a semantic theory is, however, not clear -- are established with the help of such tests. Cruse explicitly states "that a semantic feature should be regarded as firmly established only if (a) it is irtuitively convincing, (b) it is detectable contextually (including syntactically), and (c) it can be shown to have some explanatory value" (15f). By (b) Cruse understands "analytic techniques such as the do-test", i.e. semantic and syntactic tests. A clear statement 
such as this is evidence of the progress linguistics has made since 1963, when Katz and Fodor introduced semantic markers and distinguishers into transformational grammar without seeing the necessity of justifying particular features (for a critique of this procedure of. Bar-Hillel 1969: esr. 5).

\section{5.}

\section{1.}

In my opinion, there are at least the following possibilities and procedures for testing assumptions about the constituents and components of sentences: substitution for paradigmatic relationships, transformation (in a sense which may become clearer from 5.3) for paradigmatic and syntagmatic relationships, paraphrasing for certain syntactic-semantic relationships, and, in addition, a number of specific semantic tests for various semantic problems. I shall confine myself to the sentence for practical reasons, not because I believe that the symbol $\mathrm{S}$ has any exceptional status or value as a linguistic unit. Assumptions about word classes (and their subclasses) must be tested against morphological or syntactic evidence in surface structure. The latter evidence, which one could call transformational potential, can also be used in various tests for determining larger functional constituents, such as noun phrases. Distinctions and theoretical constructs which do not involve semantic differences and never show up in any way in surface structure are probably of very restricted value for a theory of language, which is not identical with a theory of language use. In the following, again for practical reasons, I shall concentrate on semantic issues with reference to the lexicon.

\section{2.}

\subsection{1.}

The importance of directly observable surface structure (in overt derivational relationships) for the justification of underlying semantic structure is demonstrated very well, I think, in Kastovsky's article on causatives (1973). Since his exposition is so clear, I can confine myseif to a few remarks. As Kastovsky points out, it can be shown that the suffixes 
of explicitly derived causative verbs such as legalize, tighten, atomize, denazify, represent an underlying element CAUSE (whether we call it a 'pre-lexical element', 'atomic predicate', or 'semantic feature' naturally depends on the model we adopt). The samc holds for zero-derivatives (cf. 3.2.3). That we have no verbs such as ${ }^{*}$ warmize, * warmen, * warmify but only warm $/ \phi$, and, on the other hand, an inchoative and causative black/en but also a causative black/ $\phi$, can be explained if we use Coseriu's concept of 'norm'. Such restrictions involve morphophonemic processes which must be accounted for in an explicit model, perhaps in a fashion similar to Weinreich's treatment of 1969. Kastovsky, following McCawley 1971 and many assumpticns of Generative Semantics, also postulates an underlying semantic elemt.nt DO. His conclusions are very similar to those drawn in a short paper by Dowty (1972), but were, as I know personally, arrived at completely independently. In all thee papers, however, the status of the underlying element DO and its relationship to the surface iexical item $d o$ is, in my iew, not made totally explicit. This is particularly clear in Douty's parer, where a second, higher DO is postulated to account for intentional causation. In a strict Generative Semantics model I see no possibility for distinguishing the two DOs (denoting activity or intention) in any way. It seems that in some treaments within the framework of Generative Semantics there is confusion of metalanguage and object language.

\subsection{2.}

5.2.2.1. The theoretical element CAUSE is motivated in Generative Semantics through paraphrasing. I have used this technique myself in Lipka 1972. It is also supported by Kastovsky's argument of using explicit causative constructions with a causative auxiliary. In Kastovsky 1974a a very interesting attempt at a synthesis of structural semantics, generitive semantics, and case grammar is made. The results of componentia analysis are converted there into generative rules. However, several cbservations cast doubt on the objectivity of paraphrasing, although I stil1 believe that it is an extremely important procedure for discovering cardidates to be postulated as underlying elements. The change from the eariy McCawley analysis of kill as CAUSE BECOME NOT ALIVE to the later DO CAUSE BECOME NOT AIJIVE should make one suspicious. Bolinger's re-analysis of remind (1971) as consisting of MAKE THINK, opposed to Postal's earlier exical decomposition into STRIKE LIKE $\mathrm{cr}$ STRIKE SIMILAR, should strengthen these suspicions. One of the rea 
sons for confusion is surely the wide-spread disregard for the probiems connected with acceptahility (cf. Lipka 1971b). Bolinger gives many examples where he disagrees with Postal on acceptability and unaccepiability of particular sentences. If, however, we only draw conclusions from the idiolect of the analyst as informant, the relevance of such conclusions for a whole language or even linguistic universals becomes rather questiona.e (cf. Householder 1973).

5.2. 2.2. The status of CAUSE may also be discussed from other points of view. If we look at its relationship with the surface item cause, at least two such items can be distinguished. If the verb cause is defined by paraphrase as 'be cause of' - parallel to the verbs bully, captain, father, pilot, witness etc. - then it clearly is a denominal zero-derivative from the noun cause. It is apparently not clear in what way this nature of the object language element cause in a paraphrase could affect its status as the metalinguistic unit CAUSE. The of in the paraphrase 'be cause of' for the verb cause also shows the relational nature of the derived surface item. The relational nature of the corresponding underlying element CAUSE, whether seen as a semantic feature or an atomic predicate, has been pointed out repeatedly in the literature, e.g. by Bierwisch. If CAUSE is represented on the surface by $-i z e,-i f y,-e n$, then it is part of the respective derivative. If CAUSE representing agentivity is seen as neither inherent in 'agentive nouns' nor 'agentive verbs' (cf. Cruse 1973), but as basically a possible relation between noun and verb, a conflict arises which raust be solved.

\subsection{3.}

The third type of evidence for the justification of underlying semantic elements, besides morphological surface structure, and paraphrase relationship, is the use of specially developed semantic tests, such as the buttest the and-test, and the $d o$-test. This subject has been discussed in 4.2.5. Tests may serve to discover and justify particular semantic features such as $[ \pm$ Together] or $[ \pm$ Stative], or to determine whether two lexical items should be regarded as the same or different (cf. 3.2.5). All three procedures, morphological analysis, paraphrase evaluation, and semantic tests, can be used to support theoretical assumptions and specific claims about underlying strucure. They have in common that they are not based on the subjective intuition of individuals. 
5.3.

There are several ways in which a non-specialized notion of transformation may be helpful. If transformations are regarded as relating s!urface structures such as active and passive sentences to each other, as was done in Syntactic Structures, then they change the positions of certain constituents such as adjectives or noun phrases in surface structure. From this change, or the possibility of undergoing such a change, conclusions may be drawn as to the classification of these elements, e.g. as transpositional or semantic adjectives and as noun phrases. This is a question of paradigmatic relationships. Syntagmatic relationships concerning both syntactic and semantic matters come into play when we regard the relationship between presidential adiser, heavy smoker, and Someone advises the president, Someone smokes heavily. According to Marchand, the former are mere transpositions, since nominalization here does not involve additional semantic features. According to Chomsky, such nominalizations (possibly including Jespersen's early riser type) would be explained $b y$, the transformational hypothesis. If the different surface structures are judged to be synonymous, they must be regarded as paraphrases. The paraphrases could be derived from a common underlying semantic structure, with the help of transformations, including prelexical transfornations, as is done in Generative Semantics. This would account for the relationship between Kastovsky's examples The court made bussing legal vs. The courr legalized bussing, or the examiples in Lipka 197 ?: Someone blocks up the river with a dam vs. Someone dams up the river, Someone drives out snakes with smoke vs. Someone smokes out snakes. In Interpretative Semantics, synonymous surface structures would be derived from a common source by meaning-preserving transformations. Morphologically unre lated, or only partially related surface structures, such as buy/sell. kill/dio, steal/thief, legalize/make legal must, however, be derived from completely different structures in such a model.

6.

I have tried io show in this article that rediscovery can be and has been a powerful stimulus for progress in linguistics. The discussion of various cases of rediscovery has also shown, I believe, that certain procedures 
are preferable to others for several reasons. I will draw the following conclusions:

(1) Reading should come before publishing. This is an old principle of scholarly tradition which could save the indivicual scholar and the rest of us a great deal of trouble. I believe that disregard and neglect of previous work is responsible for the terrifying flood of more or less accessible publications, something which Makkai (1971) has labelled "progr pollution". A 'publication" should also deserve this name and not be a euphemism for clandestine circulation of papers in hermetic circles.

(2) Testing should come before postulating a theory or claiming an underlying element. So-called progress in linguistics, with a daily fundamental change of theories, would not be as breath-taking, but real progress would probably have been greater, had this principle been observed more often. Much of the above applies here, including conclusion (1). The poblem of acceptability is a particularly revealing case in point (cf. Householder 1973).

(3) Underlying elements, which are not directly observable, should be justified by using objectively verifiable evidence. Theoretical assumptions are always necessary, but they should always be treated as such and should not be made gratuitously or entirely for reasons of elegance of the theory.

\section{References}

Bal-Hiilel, Y., 1969. Universal senantics and philosophy cf language: Quaadaries and prospects. In. Puhvel ed. 1969, 1-2.1.

Bazell, C.E., J.C. Catford, M.A.K. Halliday, R.H. Robins, (eds.), 1966. In Memory of J.R. Firth. New York: Fernhill.

Binnick, R.I., 1970. Ambiguity and Vagueness. Papers frum the 6th Regional Meeting, Chicago Linguistic Society (=CLS VI), 147-153.

Bolinger, D., 1971. Semantic overloading: A restudy of the verb REMIND. Janguage 47, $52.2-54$ ?

Bu inger, D., 1973. Truth is a linguistic question. Language $49,539-550$.

Bo ha, R.P., 1968. The function of the lexicon in trarsformational generative grammar. The Tague/Paris: Mouton.

Brek le, H.E. and L Lipka, (eds.), 1968. Wortbildung, Syntax und Morphologie. Festschrift zum 6.) Groburtstag von Hans Marchand. The Hague/Paris; Mouton.

Cin's's, C.E., 1969. Markedness, neutralization, and universal redundarcy rules. Language 45, $853-885$.

Ch.fe, W.L., 1970. Meaning and the stiucture of language. Chicago/London: Chicago Univ. Press.

Choms.cy, N., 1957. Syntactic structures. The Hague/Paris: Mouton.

Chom:ky, N., 1965. Aspects of the theory of syntax. Cambridge, Mass.: MIrT Press. 
Chomsky, N., 1970. Remarks on nominalization. In: Jacobs/Rosenbaum (eds.), 1970, 184-221.

Chomsky, N., 1971. Deep structure, surface structure, and semantic interpretation. Ja: Steinberg/Jakobovits (eds.), 1971, 183-216.

Chomsky, N. and M. Halle, 1968. The sound pattern of English. New York/Evanston/London: Harper and Row.

Cruse, D.A., 1973. Some thoughts on aguntivity. Journal of Linguistics 9, 11-23.

Dik, S.C., 1967. Some critical remarks on the treatment of morphological structure in transformational generative grammar. Lingua 18, 352-383.

Dowty, D.R., 1972. On the syntax and semantics of the atomic predicate CAUSE. CLS VIII, $62-74$.

Fillmore, Ch.J. 1966. Deictic categories in the semantics of 'Come'. Foundations of Language 2, $219-227$.

F:llmore, Ch.J., 1969/71. Types of lexical information. In Steinberg/Jakobovits (eds.), 1971, $370-392$.

Fillmore, Ch.J. and D.T. Langendoen (əds.), 1971. Studies in linguistic semantics. New York: Holt, Rinehart and Winston.

Fries, Ch.C., 1952. The structure of English. An introduction to the construction of English sentences. New York/Chicago: Harcourt Brace.

Garner, $\mathbf{R}, 1971$. 7 resupposition in philosophy and linguistics. In: Filimore/Langendoen (eds.), $1971,23-42$.

Gleason, H.A., Jr., 1961. An introduıtion to descriptive linguistics. Rev. Ed. New York/Chicago: Holi. Rinehart and Wirston.

Green, G.M., 1469. On the notion 'Rtlated lexical entry'. CLS V. 76-88.

Green, G.M., 1973. The lexical expression of emphatic conjunction. Theoretical implications. Foundations of Language 10, 197-248.

Halle, M. 1973. Prolegomena to a theory of word formation. Linguistic Inquiry $4,3-16$.

Hall Partee, B., 1971. On the requirernent that transformations preserve meaning. In: Fillmore/ Langendoen (eds.), 1971, 1-21.

Householder, F. W., 1973. On arguments from asterisks. Foundations of Language 10, 365-376.

Jacobs, R.A. and P.S. Rosenbaum, 1968. English iransformational grammar. Toronto/London: Blaisdell Publ. Co.

Jacobs, R.A. and F.S. Rosenbaum (eds.), 1970. Readings in English transformational grammar. Toronto/London: Ginn.

Kastovsky, D '968. Old English deverba' ubstantives derived by means of a zero morpheme. Diss. Tiib. 2n.

Kastovsky, D., 1971. Studies in morphology. Aspects of English and German verb inflection. Tübingen (= $\mathrm{T}$, inger Beitroge zur Linguistik 18)

Kastovsky, D., 19/3. Causatives. Foundations of La uage 10, 255-315.

Kastovsky, D., 1974a. Word-formation, case grammar, and denominal adjectives. r.nglia 92, $1-54$.

Kastovsky, D. (ed.), 1974b. Studies in syntax and word-formation. Selected articles of Hans Marchand München: Fink.

King, R.T 1974. Modern semantic theory: A critical analysis and an application to the study of Ge an prepositions. Houston: Rice University, Diss. (Microfilm).

Lakoff, G., 1970. A note on vagueness and ambiguity. :inguistic Inquiry 1, 357-359.

Lak off, $R, 1972$. Language in context. Language 48, 907-927.

Leisi, E., 1971. Der Wortinhalt. Seine Struktur im Deutschen und Englischen. 4th ed. Heideiberg: Quelle und Meyer.

Lipka, L, 1966. Die Wortbildungstypen WATERPROOF und GRASS-GREEN und ihre Entsprechung im Deutschen. Diss. Tübingen. 
Lipka, L., 1968. Kugelsicher - à l'épreuve des balles. Eine Lücke im Wortbildungssystem cles Französischen. In: Brekle/Lipka (eds.), 1968, $127 \quad 142$.

Lipka, L., 1969. Assimilation and dissimilation ac regulating factors in English morphology. Zeitschrift für Anglistik und Amerikanistik 17, 159-173.

Lipka, L., 1971a. Grammatical categories, lexical items, and word-formation. Foundations of Language 7, 211-238.

Lipk̀a, L., 1971 b. Grammatikalität, Akzeptabilität und Produktivität in der Sprache. In: A. von Stechow (ed.), Beiträge zur generativen Grammatik. Referate des 5. Finguistischen Kclloquiums Regensburg, 1970. Braunschweig: Vieweg, 142-151.

Lipka, L., 2. 2. Seinantic structure and word-formation. Verb-particle constructions in contempo: ary Englich. Mürichen: Fink.

Lyons, J., 1966. Firth's theory of 'Meaning'. In: Bazell et al. (eds.), 1966, 288--308.

Lyons, J., 1968. Introduction to theoretical linguistics. London: Cambridge Iniv. Press.

Lyons, J. (ed.), (1970), New horizons in linguistics. Harmondsworth: Penguin.

Makkai, A., 1971. Degrees of nonsense, or transformation, stratification, and the contextual adjustibility principle. CLS VII, 479-492.

Marchand, H., 1966a. Review of: K.E. Zimmer, Affixal negation in English and other languages. Language 42, 134-142.

Marchand, K., 1966b. On attributive and predicative derived adjectives and some problems related to the distinction. Anglia $84,131-14^{n}$.

Marchand, H., 1969. The categories and types of present-day English word-formation. A synchronic-diachronic approach. 2nd ed. Mïnchen: C.H. Beck.

Mat thews, P.H., 1972. Inflectional morphology; a theoretical study based on aspects of Latin verb conjugation. London: Cambridge Univ. Press.

McCáwley, J.D., 1968a. Lexical insertion in a transformational grammar without decp struc"ure. CLS IV, 71-80.

McCawley, J.D., 1968b. Concerning the base component of a transformational grammar. Foundations of Language 4, 243-269.

McCawley, J.D., 1971. Prelexical syntax. In: R.J. O’Brien (ed.), 22nd Annual Round Table. Linguistics: Developments of the sixties - Viewpoints for the seventies. Monograph Series on Languages anc inguistics 24, Georgetown (1971), 19-33.

Miller, J., 1973. A note on so-called 'Discovery Procedures'. Fuundations of Language 10, $123-139$.

Monaghan, $I$., for thcoming. The neo-Firthian tradition in linguistics: A contribution towards a synthesis.

Motsch, W., 1962. Zur Stellung der 'Wortbildung' in einem formalen Sprachmodell. Studia Grammatica 1, 31-50.

Neuhaus, H. J., 1971. Beschränkungen in der Grammatik der Wortableitungen im Englischen. Diss. Saarbrücken.

Newmeyer, 17.J., 1971. The source of derived nominals in English. Language 47, 786-796.

Nida, E.A., 1949. Morphology, The descriptive analysis of words. 2nd ed. Ann Arbor: Univ. of Michigan ?ress.

Pennanen, F., 1972. Current views of word-formation. Neuphilologische Mitteilungen 73, $292-308$.

Puhvel, J. (ed.), 1969. Substance and structure of language. Berkeley/Los Angeles: Univ. of California Press.

Rose, J.H., 1973. Principled limitations on productivity in denominal verbs. Foundations of Language 10, 509-526.

Stein, G., 1971. Primäre und sekundäre Adjektive im Französischen und Englischen. Diss. Tübingen. (=Tübinger Beiträge zur Linguistik 22). 
Stein, G., 1973. English word-formation over two centuries. In Honour of Hans Marchand on the Occasion of his Sixty-Fifth Birthday. Tübingen. (=Tübinger Beiträge Zur Linguistik 34).

Steinberg, D.D. and I.A. Jakobovits (eds.), 1971. Semantics. An interdisciplinary reader in phi osophy, linguistics, and psychology. London: Cambridge Univ. Press.

Vachel, J., 1966. The linguistic school of Prague. An introduction to its theo: $v$ and practice. Blo smington/London: Indiana Univ. Press.

Weinreich, U., 1966. Explorations in semantic theory. In: T.A. Sebeok, (ed.), 1966, Current trends in linguistics 3. The Hague: Mouton, 395-477.

Weinreich, U., 1959. Prot,uems in the analysis of iclioms. In: Puhvel (ed.), 1969, 23-81.

Weydt, H., 1973. On G. Lakoff, 'Instrumental adverbs and the concept of deep structure', Foundations of Language 10,569-578.

Wurzะi, W.U., 1770. Studien zur deutschen Lautstruktur. Berlin (=Studia Grammatica 8). 